\title{
Out-of-hospital cardiac arrest: data from the National Registry of Invasive Cardiology Procedures (ORPKI) in a long-term survival analysis of patients with acute coronary syndromes in a Polish region
}

\author{
Janusz Sielski, Karol Kaziród-Wolski, Zbigniew Siudak \\ Collegium Medicum, The Jan Kochanowski University, Kielce, Poland
}

\section{KEY WORDS \\ acute coronary syndromes, out-of- -hospital cardiac arrest, percutaneous coronary intervention}

\section{EDITORIAL}

by Gräsner, Tjelmeland, Wnent, see p. 379
Correspondence to: Karol Kaziród-Wolski, MD, $\mathrm{PhD}$, Collegium Medicum, The Jan Kochanowski University, al. IX Wieków Kielc 19a, 25-317 Kielce, Poland, phone: +48413496935, email: karol.kazirod-wolski@ujk.edu.pl Received: December 4, 2019. Revision accepted: March 22, 2020

Published online: March 23, 2020. Kardiol Pol. 2020; 78 (5): 412-419 doi:10.33963/KP.15244 Copyright by the Author(s), 2020

\section{ABSTRACT}

BACKGROUND Out-of-hospital cardiac arrest (OHCA) is one of the leading causes of death in high-income countries.

AIMS This study aimed to analyze long-term survival in patients with OHCA in the Świętokrzyskie Province, who were included in the National Registry of Invasive Cardiology Procedures (ORPKI), estimate survival probability, and evaluate associated risk factors.

METHODS Based on the ORPKI registry, we identified subjects with OHCA prior to hospitalization. Data were collected from January 1, 2014 to December 31, 2016.

RESULTS Out-of-hospital cardiac arrest occurred in 90 of 9855 patients diagnosed with myocardial infarction. We identified 2 significant risk factors: renal failure (HR, 6.53; 95\% CI, 1.17-36.40; $P=0.03$ ) and time (hours) from symptom onset to first medical contact (HR, 1.04; 95\% CI, 1.01-1.08; $P=0.02)$. The probability of survival in patients below 66 years of age was almost 2-fold higher (HR, 1.99; $95 \% \mathrm{CI}$, 1.1-3.59; $P=0.02$ ) than in those over the age of 66 years. In those without diabetes mellitus, it was more than 2-fold higher (HR, 2.36; 95\% CI, 1.12-4.98; $P=0.03$ ) than in diabetic patients, and in individuals with single-vessel coronary artery disease, it was almost 3-fold higher (HR, 2.76; 95\% CI, 1.51-5.06; $P=0.001)$ than in those with multivessel coronary artery disease.

CONCLUSIONS Well-documented predictors of all-cause mortality include: age, history of diabetes mellitus and renal failure, multivessel coronary artery disease on angiography, and time from pain onset to first medical contact. The total amount of contrast agent administered during invasive procedures and patient radiation exposure during procedures are less commonly reported risk factors for unfavorable outcomes.

INTRODUCTION Registry studies together with randomized controlled trials are considered extremely valuable sources of medical knowledge. However, randomized trials may appear unfeasible for certain clinical endpoints. In such cases, clinical data registries are the only source of information about patients' health status. Reliable data collected in registries provide useful and reliable facts. Meta-analyses of registry studies improve our understanding of the diagnosis and management of particular diseases. The occurrence of out-of-hospital cardiac arrest (OHCA) has also been recorded for many years, both in Europe and on a national scale. ${ }^{1-3}$ In Poland, there 


\section{WHAT'S NEW?}

This is the first study based on the National Registry of Invasive Cardiology Procedures (Polish, Ogólnopolski Rejestr Procedur Kardiologii Inwazyjnej [ORPKI]), which presents a less standard patient evaluation, ie, a survival analysis of patients with coronary artery syndromes and out-of-hospital cardiac arrest. The study evaluated clinical and procedural risk factors reported in this population: the radiation dose absorbed by patients and the total amount of contrast agent administered during invasive procedures. We suggest developing a national registry of cases of out-of-hospital cardiac arrest, which could help optimize outcomes in this group of patients.

are several small OHCA databases, but no national OHCA registry is available. ${ }^{4-6}$

Out-of-hospital cardiac arrest is one of the leading causes of death in high-income countries. ${ }^{7}$ In Europe, its incidence is 40 cases per 100000 adults annually. ${ }^{8}$ Acute coronary syndromes (ACSs) are the most frequent cause of OHCA, with $76 \%$ of cases currently attributed to ACSs. ${ }^{9}$ Well-designed and structured registries, which gather information on OHCA, are good sources of data for clinical research, for instance, in Australia, Japan, and Denmark..$^{10-12}$ They provide relevant information on the etiology and pathogenesis of OHCA. The OHCA databases include also data regarding ACS, which is considered the reason for OHCA. Currently, there is no national OHCA registry in Poland. Data on the cases of OHCA are collected in the Silesia and Świętokrzyskie provinces., ${ }^{41}$ The National Registry of Invasive Cardiology Procedures (ORPKI) was launched on January 1, 2014. ${ }^{14}$ In this project undertaken by Jagiellonian University Medical College (Kraków, Poland) and the Association of Cardiovascular Interventions of the Polish Cardiac Society, data from 161 catheterization laboratories are collected. A more detailed description of the registry was presented elsewhere. ${ }^{14,15}$

The objective of the present study was to analyze long-term survival of patients with OHCA identified in the ORPKI registry for the Świętokrzyskie Province, estimate their probability of survival, and evaluate risk factors.

METHOdS The Świętokrzyskie Province is a small region, 1 of the 16 provinces in Poland, which is a member state of the European Union. Based on data from 2016, the province covered the area of $11711 \mathrm{~km}^{2}$, was inhabited by 1.25 million people, and its population density was 108 people per $1 \mathrm{~km}^{2}$ of land area. ${ }^{16}$ Currently, there are 6 catheterization laboratories in the Świętokrzyskie Province ${ }^{17}$ (Supplementary material, Figure S1). In Europe, mortality due to cardiovascular disease (CVD) decreased in the last 25 years. However, its incidence has increased: in 2015, about 11.3 million new cases of CVD were diagnosed, constituting more than 85 million people living with CVD.18
Fast transport of patients to the nearest catheterization laboratory, which shortens time between first medical contact and device implantation, is one of the components of an algorithm for emergency medical services. The medical team of the Świętokrzyskie Cardiology Center has been developing this approach for a number of years, using a telecommunication system and a network of emergency medical service stations (Supplementary material, Figure S2). ${ }^{19}$ The population of patients transferred directly to the nearest catheterization laboratory to undergo invasive procedures includes also those with OHCA. Based on the ORPKI registry, which contains detailed procedural information about patients with ACSs, we identified subjects with OHCA prior to hospitalization (Supplementary material, Figure S3). There were 2 groups of patients: 1) group A-all patients in the ORPKI database; and 2) group B-patients with OHCA identified in the ORPKI registry. These data were matched with records from the Świętokrzyskie branch of the Polish National Health Fund (Polish, Narodowy Fundusz Zdrowia [NFZ]) in order to provide a reliable long-term follow-up.

The study was based on retrospective registry data. No ethics committee approval nor patient consent were required.

Statistical analysis Quantitative variables were expressed as mean (SD) and median (interquartile range). Categorical variables were presented as numbers and percentages. The normality of data distribution was tested with the Shapiro-Wilk test and the Kolmogorov-Smirnov test. The $\mathrm{X}^{2}$ test and the Fisher exact test were used to evaluate the statistical significance of differences for single classifications and to test the interdependence of pairs of variables for double classifications. The $t$ test for normally distributed variables and the Mann-Whitney test for nonnormally distributed variables were applied to assess within-group differences. The univariate and multiple Cox regression models were used to estimate hazard ratios with $95 \%$ CIs and $P$ values. The Kaplan-Meier survival analysis and the log-rank test were used for estimation of survival probability at a particular point in time (30 days, 1 year, 2 years), risk ratios, and $P$ values for the log-rank test. A $P$ value less than 0.05 was considered significant. ${ }^{20}$ Statistical analysis was performed using the MedCalc Statistical Software, version 17.2 (MedCalc Software, Ostend, Belgium).

RESULTS A total of 9855 patients diagnosed with myocardial infarction and admitted to catheterization laboratories in the Świętokrzyskie Province between 2014 and 2016 were included in this study. Clinical characteristics of the study group obtained from the ORPKI database are 
TABLE 1 Characteristics of the Świętokrzyskie Province population admitted to the hospital with the diagnosis of acute coronary syndromes (group A)

\begin{tabular}{|c|c|c|c|c|c|}
\hline \multicolumn{2}{|l|}{ Variable } & $\begin{array}{l}\text { Total } \\
(n=9855)\end{array}$ & $\begin{array}{l}\text { Non-PCI group } \\
(n=3324[33.7 \%])\end{array}$ & $\begin{array}{l}\text { PCI group } \\
(n=6531[66.3 \%])\end{array}$ & $P$ value \\
\hline \multirow[t]{2}{*}{ Sex } & Male & 6531 (66.3) & $1873(56.3)$ & $4366(66.9)$ & \multirow[t]{2}{*}{$<0.001$} \\
\hline & Female & $3616(36.7)$ & $1451(43.7)$ & $2165(33.1)$ & \\
\hline \multicolumn{2}{|c|}{ Age at first procedure, $y$, mean (SD) } & $67.4(10.9)$ & $67.4(10.3)$ & $67.5(11.2)$ & 0.57 \\
\hline \multicolumn{2}{|l|}{ Weight, kg, mean (SD) } & $79.5(14.5)$ & $79.1(14.3)$ & $79.7(14.5)$ & 0.01 \\
\hline \multicolumn{2}{|l|}{ Diabetes mellitus } & $2030(20.6)$ & $601(18.1)$ & $1429(21.9)$ & $<0.001$ \\
\hline \multicolumn{2}{|l|}{ Previous stroke } & $323(3.3)$ & $100(3)$ & $223(3.4)$ & 0.29 \\
\hline \multicolumn{2}{|l|}{ Previous MI } & $1843(18.7)$ & $631(19)$ & $1212(18.6)$ & 0.61 \\
\hline \multicolumn{2}{|l|}{ Previous PCI } & $1615(16.4)$ & $542(16.3)$ & $1073(16.4)$ & 0.88 \\
\hline \multicolumn{2}{|l|}{ Previous CABG } & $411(4.2)$ & $134(4)$ & $277(4)$ & 0.62 \\
\hline \multicolumn{2}{|l|}{ Smoking status } & $1890(19.2)$ & $464(14)$ & $1426(21.8)$ & $<0.001$ \\
\hline \multicolumn{2}{|l|}{ Psoriasis } & $42(0.4)$ & $15(0.5)$ & $27(0.4)$ & 0.79 \\
\hline \multicolumn{2}{|l|}{ Arterial hypertension } & $6925(70.3)$ & $2319(69.8)$ & $4606(70.5)$ & 0.44 \\
\hline \multicolumn{2}{|l|}{ Kidney disease } & $382(3.9)$ & $121(3.6)$ & $261(4)$ & 0.39 \\
\hline \multicolumn{2}{|l|}{ COPD } & $113(1.6)$ & $44(1.9)$ & $69(1.5)$ & 0.22 \\
\hline \multirow{3}{*}{$\begin{array}{l}\text { Approach for coronary } \\
\text { angiography }\end{array}$} & Femoral & $3557(36.3)$ & $1016(30.6)$ & $2541(39.3)$ & \multirow[t]{3}{*}{$<0.001$} \\
\hline & Radial & $6209(63.4)$ & $2290(69.1)$ & $3919(60.6)$ & \\
\hline & Other & $21(0.2)$ & $9(0.3)$ & $12(0.2)$ & \\
\hline \multirow[t]{3}{*}{ Coronary artery status } & $\begin{array}{l}\text { Nonsignificant } \\
\text { changes }\end{array}$ & $2192(22.4)$ & $2088(62.9)$ & $104(1.6)$ & \multirow[t]{3}{*}{$<0.001$} \\
\hline & $\begin{array}{l}\text { Single-vessel } \\
\text { disease }\end{array}$ & $3620(37)$ & $188(5.7)$ & 3432 (53.1) & \\
\hline & $\begin{array}{l}\text { Multivessel } \\
\text { disease } \\
\text { and/or LMCA }\end{array}$ & 3975 (40.6) & $1045(31.5)$ & $2930(45.3)$ & \\
\hline \multicolumn{2}{|c|}{$\begin{array}{l}\text { Time from pain onset to first medical } \\
\text { contact, h, median (IQR) }\end{array}$} & $2.58(1-7)$ & $4(1.6-14)$ & $2.5(1-6.5)$ & $<0.001$ \\
\hline \multicolumn{2}{|c|}{$\begin{array}{l}\text { Time from first medical contact to } \\
\text { inflation, h, median (IQR) }\end{array}$} & $2(1-6.3)$ & $6.48(2-20.4)$ & $1.92(1-5.3)$ & $<0.001$ \\
\hline \multicolumn{2}{|l|}{$\begin{array}{l}\text { Time from pain onset to } \\
\text { inflation, h, median (IQR) }\end{array}$} & $6.28(3-20.6)$ & $18(6.5-36.5)$ & $5.67(2.9-17.5)$ & $<0.001$ \\
\hline \multicolumn{2}{|c|}{$\begin{array}{l}\text { Total amount of contrast agent during } \\
\text { angiography, ml, mean (SD) }\end{array}$} & $156(81)$ & $90(51)$ & $190(73)$ & $<0.001$ \\
\hline \multicolumn{2}{|c|}{$\begin{array}{l}\text { Absorbed radiation dose during } \\
\text { angiography, mGy, mean (SD) }\end{array}$} & $930(902)$ & $442(400)$ & 1175 (981) & $<0.001$ \\
\hline \multicolumn{2}{|l|}{ Death } & 1292 (13.1) & 386 (11.6) & $906(13.9)$ & 0.002 \\
\hline
\end{tabular}

Data are presented as number (percentage) unless otherwise indicated.

Abbreviations: CABG, coronary artery bypass grafting; COPD, chronic obstructive pulmonary disease; IQR, interquartile range; LMCA, left main coronary artery; mGy, miligrays; MI, myocardial infarction; PCI, percutaneous coronary intervention

summarized in TABLE 1. There were 90 individuals $(0.9 \%)$ with OHCA: 57 men and 33 women (73.3\% and $36.7 \%$, respectively). Percutaneous coronary intervention (PCI) was performed in 77 patients (86\%). No significant differences were found between men and women. Clinical characteristics of patients are presented in TABLE2. The characteristics of all cases of OHCA in this region are shown in Supplementary material,
Table S1. Factors that can influence survival in patients with ACS and OHCA were analyzed using the Cox regression model and the KaplanMeier curves. Univariate regression analysis demonstrated that survival after OHCA significantly depended on the factors summarized in TABLE3. Multivariate Cox regression analysis using the enter method identified 2 significant risk factors: renal failure (HR, 6.53; 95\% CI, 1.17-36.4; 
TABLE 2 Characteristics of patients admitted to the hospital after out-of-hospital cardiac arrest (group B)

\begin{tabular}{|c|c|c|c|c|c|}
\hline \multicolumn{2}{|l|}{ Variable } & $\begin{array}{l}\text { Total } \\
(n=90)\end{array}$ & $\begin{array}{l}\text { Non-PCI group } \\
(n=13[14.4 \%])\end{array}$ & $\begin{array}{l}\text { PCI group } \\
(n=77[65.6 \%])\end{array}$ & $P$ value \\
\hline \multirow[t]{2}{*}{ Sex } & Male & $57(63.3)$ & $8(61.5)$ & $49(63.6)$ & \multirow[t]{2}{*}{0.89} \\
\hline & Female & $33(36.7)$ & $5(38.5)$ & $28(36.4)$ & \\
\hline \multicolumn{2}{|c|}{ Age at first procedure, y, mean (SD) } & $67.75(11.35)$ & $68.3(14.99)$ & $67.66(10.75)$ & 0.59 \\
\hline \multicolumn{2}{|l|}{ Weight, kg, mean (SD) } & $77.03(15.68)$ & $72.77(14.64)$ & $77.75(15.83)$ & 0.25 \\
\hline \multicolumn{2}{|l|}{ Diabetes mellitus } & $20(22.2)$ & $3(23.1)$ & $17(22.1)$ & 0.94 \\
\hline \multicolumn{2}{|l|}{ Previous stroke } & $1(1.1)$ & 0 & $1(1.3)$ & 0.68 \\
\hline \multicolumn{2}{|l|}{ Previous MI } & $15(16.7)$ & $4(30.8)$ & $11(14.3)$ & 0.14 \\
\hline \multicolumn{2}{|l|}{ Previous PCI } & $10(11.1)$ & $2(15.4)$ & $8(10.4)$ & 0.6 \\
\hline \multicolumn{2}{|l|}{ Previous CABG } & $1(1.1)$ & 0 & $1(1.1)$ & 0.68 \\
\hline \multicolumn{2}{|l|}{ Smoking status } & $23(25.6)$ & $3(23.1)$ & $20(26)$ & 0.82 \\
\hline \multicolumn{2}{|l|}{ Psoriasis } & $1(1.1)$ & 0 & $1(1.3)$ & 0.68 \\
\hline \multicolumn{2}{|l|}{ Arterial hypertension } & $48(53.3)$ & $3(23.1)$ & $45(58.4)$ & 0.02 \\
\hline \multicolumn{2}{|l|}{ Kidney disease } & $4(4.4)$ & $2(15.4)$ & $2(2.6)$ & 0.04 \\
\hline \multicolumn{2}{|l|}{ COPD } & $3(4.7)$ & 0 & $3(5.5)$ & 0.48 \\
\hline \multirow{3}{*}{$\begin{array}{l}\text { Diagnosis at discharge } \\
\text { (based on medical history) }\end{array}$} & NSTEMI & $13(14.4)$ & $4(30.8)$ & $9(11.7)$ & \multirow[t]{3}{*}{0.001} \\
\hline & STEMI & $61(67.8)$ & $3(23.1)$ & $58(75.3)$ & \\
\hline & $\begin{array}{l}\text { Status post } \\
\text { cardiac arrest }\end{array}$ & $16(17.8)$ & $6(46.2)$ & $10(13)$ & \\
\hline \multirow{2}{*}{$\begin{array}{l}\text { Approach for coronary } \\
\text { angiography }\end{array}$} & Femoral & $57(63.3)$ & $7(53.8)$ & $50(64.9)$ & \multirow[t]{2}{*}{0.45} \\
\hline & Radial & $33(36.7)$ & $6(46.2)$ & $27(35.1)$ & \\
\hline \multirow[t]{3}{*}{ Coronary artery status } & $\begin{array}{l}\text { Nonsignificant } \\
\text { changes }\end{array}$ & $7(7.8)$ & $7(53.8)$ & 0 & \multirow[t]{3}{*}{$<0.001$} \\
\hline & $\begin{array}{l}\text { Single-vessel } \\
\text { disease }\end{array}$ & $38(42.2)$ & $2(15.4)$ & $36(46.8)$ & \\
\hline & $\begin{array}{l}\text { Multivessel } \\
\text { disease and / or } \\
\text { LMCA }\end{array}$ & $45(50)$ & $4(30.8)$ & $41(53.2)$ & \\
\hline \multicolumn{2}{|c|}{$\begin{array}{l}\text { Time from pain onset to first medical contact, } \\
h \text {, median (IQR) }\end{array}$} & $1(0.7-2.1)$ & $0.83(0.6-1)$ & $1(0.8-2.2)$ & 0.25 \\
\hline \multicolumn{2}{|c|}{$\begin{array}{l}\text { Time from first medical contact to inflation, } \\
h \text {, median (IQR) }\end{array}$} & $1.5(0.8-2)$ & $2(1.1-2.6)$ & $1.4(0.8-1.9)$ & 0.89 \\
\hline \multicolumn{2}{|c|}{ Time from pain onset to inflation, h, median (IQR) } & $3(1.8-5.7)$ & $3(1.9-3.7)$ & $3(1.8-5.9)$ & 0.23 \\
\hline \multicolumn{2}{|c|}{$\begin{array}{l}\text { Total amount of contrast during angiography, ml, } \\
\text { mean (SD) }\end{array}$} & $173.4(84.95)$ & $70.39(34.3)$ & $193.09(77.16)$ & $<0.001$ \\
\hline \multicolumn{2}{|c|}{$\begin{array}{l}\text { Absorbed radiation dose during angiography, } \\
\text { mGy, mean (SD) }\end{array}$} & $864.41(769.18)$ & $263.92(176.79)$ & $980.93(785.93)$ & $<0.001$ \\
\hline \multicolumn{2}{|l|}{ Death } & $51(56.7)$ & $10(76.9)$ & $41(53.2)$ & 0.11 \\
\hline
\end{tabular}

Data are presented as number (percentage) unless otherwise indicated.

Abbreviations: NSTEMI, non-ST-segment elevation myocardial infarction; STEMI, ST-segment elevation myocardial infarction; others, see TABLE 1

$P=0.03)$ and time from symptom onset to first medical contact expressed in hours (HR, 1.04; 95\% CI, 1.01-1.08; $P=0.02$ ). The backward method identified 4 significant risk factors that simultaneously affected OHCA (TABLE 4). For the factors which were likely to influence survival in patients with OHCA, we estimated the probability of survival presented as Kaplan-Meier survival curves (Supplementary material, Table $S 2$ ). The probability of survival in patients below the age of 66 years was almost 2-fold higher ( $\mathrm{HR}$, 1.99; 95\% CI, 1.10-3.59; $P=0.02$ ) than in those 


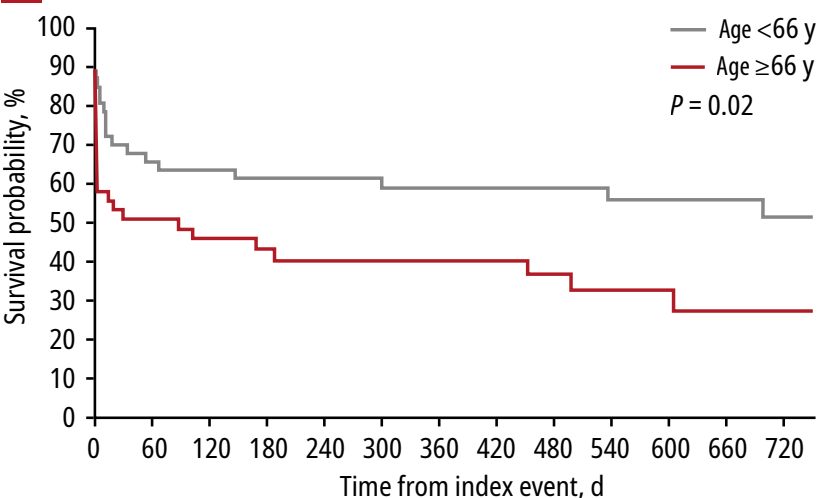

Patients at risk, $\mathrm{n}$

Age $<66$ y

423331292928272726262424232121202019181816141413119 Age $\geq 66 y$

332220191818151414131313131212119886644321

c

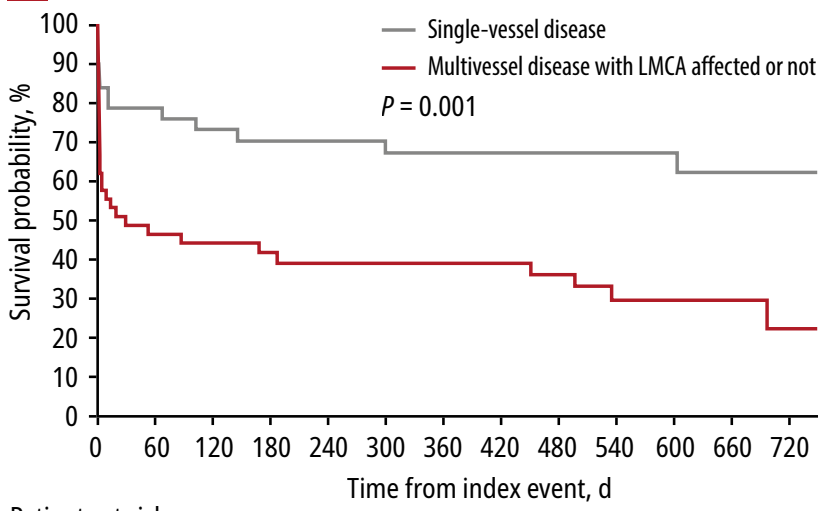

Patients at risk, $\mathrm{n}$

With single-vessel disease

34302927262523232323212121191918171616141411111197

With multivessel disease with LMCA affected or not

35222019191917161515151514131312111099766433

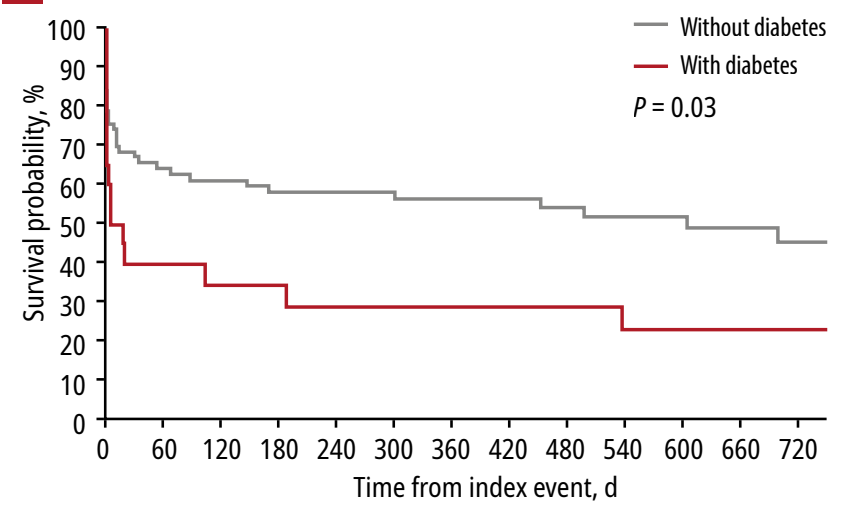

Patients at risk, $\mathrm{n}$

Without diabetes

594744414140363635343232312828262422222119161615129 With diabetes

$16 \begin{array}{lllllllllllllllllllllllll} & 8 & 7 & 7 & 6 & 6 & 6 & 5 & 5 & 5 & 5 & 5 & 5 & 5 & 5 & 5 & 5 & 5 & 4 & 3 & 3 & 2 & 2 & 1 & 1\end{array}$

D

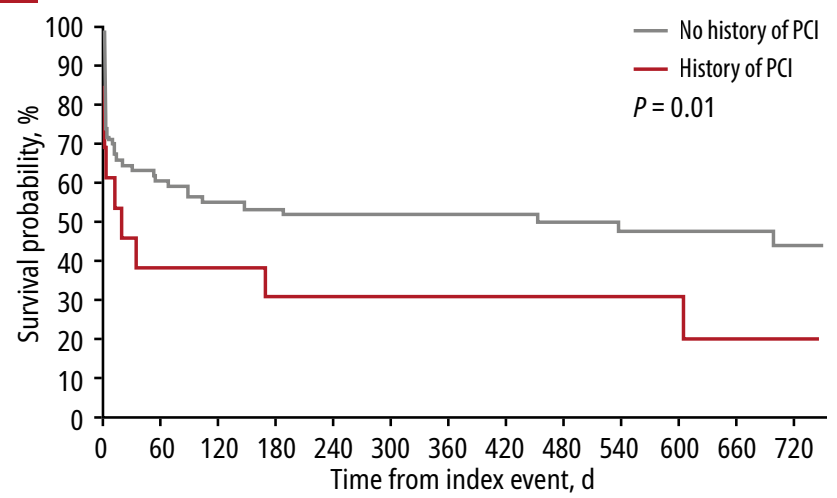

Patients at risk, $n$

No history of PCl

$\begin{array}{llllllllllllllllllllllllll}10 & 6 & 5 & 5 & 5 & 5 & 4 & 4 & 4 & 3 & 3 & 3 & 3 & 3 & 3 & 3 & 3 & 3 & 3 & 3 & 3 & 1 & 1 & 1 & 1 & 0\end{array}$ History of PCI

654844403938353433333232312828262322211917151514119

FIGURE 1 Probability of survival after out-of-hospital cardiac arrest depending on median age (A), presence of diabetes (B), status of coronary arteries (C), and history of any percutaneous coronary intervention (D)

Abbreviations: see TABLE 1

over the age of 66 years (FIGURE 1A). In subjects without diabetes mellitus, it was more than 2-fold higher (HR, 2.36; 95\% CI, 1.12-4.98; $P=0.03$ ) than in diabetic patients (FIGURE 1B). The probability of survival in patients with single-vessel coronary artery disease was almost 3-fold higher (HR, 2.76; 95\% CI, 1.51-5.06; $P=0.001$ ) than in those with multivessel coronary artery disease (FIGURE 1 C). Values noted in patients treated with PCI and those not undergoing PCI were the same (FIGURE 1D).

DISCUSSION Data on the occurrence of OHCA and ACS are collected in national registries and observational studies in many countries. ${ }^{21,22}$ Such registries serve as a basis for developing treatment strategies and guidelines for clinical practice. Currently, there is no national OHCA registry in Poland, but various research teams try to build their own databases. Therefore, extracting data from the existing registries may be very helpful and time-saving. That is why we used the ORPKI database to evaluate the management of patients with OHCA. The same registry was also used for the evaluation of patients with rare cardiovascular diseases. ${ }^{23}$ The present study assessed survival in patients with ACS and OHCA considering the effect of well-known risk predictors, such as age, diabetes mellitus, renal failure, multivessel coronary artery disease, and less commonly observed risk factors, such as the radiation dose absorbed by patients and the total amount of contrast media administered during invasive procedures. In our group of ORPKI patients, although it was relatively small, 
TABLE 3 Risk factors for all-cause mortality estimated with the univariate Cox regression model

\begin{tabular}{lll} 
Factor & HR $(95 \% \mathrm{CI})$ & P value \\
Any PCI (yes / no) & $0.56(0.28-1.11)$ & 0.1 \\
\hline Sex (male / female) & $0.75(0.43-1.3)$ & 0.3 \\
\hline Age, y & $1.04(1.01-1.06)$ & 0.01 \\
\hline Weight, kg & $0.99(0.97-1.01)$ & 0.15 \\
\hline Diabetes mellitus (yes/no) & $1.94(1.05-3.56)$ & 0.03 \\
\hline Previous myocardial infarction (yes / no) & $0.96(0.45-2.05)$ & 0.91 \\
\hline Smoking status (yes / no) & $0.62(0.32-1.22)$ & 0.17 \\
\hline Arterial hypertension (yes / no) & $1.18(0.68-2.06)$ & 0.55 \\
\hline Kidney disease (yes / no) & $2.36(0.85-6.58)$ & 0.1 \\
\hline COPD (yes / no) & $0.82(0.18-3.68)$ & 0.79 \\
\hline Killip class & $1.17(0.91-1.5)$ & 0.21 \\
\hline Approach for coronary angiography (femoral/ radial) & $1.51(0.83-2.74)$ & 0.18 \\
\hline Coronary artery status & $1.61(0.98-2.64)$ & 0.06 \\
\hline Total amount of contrast used during the procedure, ml & $0.9963(0.9926-0.9999)^{\mathrm{a}}$ & 0.046 \\
\hline Radiation dose absorbed during the procedure, mGy & $0.9995(0.9990-1.0000)^{\mathrm{a}}$ & 0.07 \\
\hline Time from first medical contact to inflation or angiography, h & $0.9954(0.9560-1.0364)^{\mathrm{a}}$ & 0.82 \\
\hline Time from pain onset to first medical contact, h & $1.03(1-1.08)$ & 0.048 \\
\hline Time from pain onset to inflation or angiography, h & $1.01(0.99-1.03)$ & 0.38 \\
\hline
\end{tabular}

a For precision, results are reported to 4 decimal places.

Abbreviations: see TABLE 1

TABLE 4 Multivariate analysis with Cox regression (including covariates with $P \leq 0.1$ in univariate analysis)

\begin{tabular}{|c|c|c|c|c|}
\hline \multirow[t]{3}{*}{ Covariate } & \multicolumn{4}{|c|}{ Methoda } \\
\hline & \multicolumn{2}{|l|}{ Enter } & \multicolumn{2}{|c|}{ Backward } \\
\hline & $\mathrm{HR}(95 \% \mathrm{CI})$ & $P$ value & $\mathrm{HR}(95 \% \mathrm{CI})$ & $P$ value \\
\hline Any PCI (yes / no) & $0.46(0.14-1.54)$ & 0.21 & NE & \\
\hline Age, y & $1.01(0.98-1.05)$ & 0.48 & $\mathrm{NE}$ & \\
\hline Diabetes (yes / no) & $1.92(0.81-4.55)$ & 0.14 & $2.59(1.19-5.65)$ & 0.02 \\
\hline Kidney disease (yes / no) & $6.53(1.17-36.40)$ & 0.03 & $9.15(2.28-36.77)$ & 0.01 \\
\hline Coronary artery status $(1 / 2 / 3)^{b}$ & $1.71(0.91-3.21)$ & 0.097 & $\mathrm{NE}$ & \\
\hline Total amount of contrast used during procedure, $\mathrm{ml}$ & $1(0.99-1.01)$ & 0.66 & NE & \\
\hline Radiation dose absorbed during procedure, mGy & $0.999(0.998-1.0002)$ & 0.098 & $0.999(0.9985-1)$ & 0.048 \\
\hline Time from pain onset to first medical contact, $\mathrm{h}$ & $1.04(1.01-1.08)$ & 0.02 & $1.05(1.01-1.08)$ & 0.01 \\
\hline Overall model fit ${ }^{c}$ & \multicolumn{2}{|c|}{$\chi^{2}=20.4 ; d f=8 ; P=0.01$} & \multicolumn{2}{|c|}{$\chi^{2}=18.1 ; d f=4 ; P=0.001$} \\
\hline
\end{tabular}

a Selected based on the way in which the independent variables were entered into the model. Enter: all variables were entered into the model in a single step, without checking. Backward: all variables were first entered into the model and then the nonsignificant variables were removed sequentially.

b 1 - nonsignificant changes; 2 - single-vessel disease; 3 - multivessel disease and / or LMCA

c The $\chi^{2}$ tests of the relationship between time and all covariates in the model.

Abbreviations: NE, not entered into the model using the backward algorithm; others, see TABLE 1 
age and a history of diabetes mellitus and renal failure were associated with worse survival after ACS and OHCA. Kroupa et $\mathrm{al}^{24}$ obtained similar results in a group of 108 patients with ACS undergoing invasive procedures $(66 \%$ of them had OHCA). Mortality was related to age, a history of diabetes mellitus, and arrhythmia. ${ }^{24}$ Tateishi et $\mathrm{al}^{25}$ studied the effect of the number of coronary lesions on survival after ACS and OHCA. In a group of 2779 patients, mortality was higher in those with multivessel coronary artery disease than in those with single-vessel disease. ${ }^{25}$ In a large study, the RAD-MATRIX (the radiation substudy of the Minimizing Adverse Haemorrhagic Events by Transradial Access Site and Systemic Implementation of AngioX) trial carried out in almost 8500 patients with ACS, Sciahbasi et $\mathrm{al}^{26}$ compared operator and patient radiation exposure in relation to the arterial access site for diagnostic and interventional procedures. The authors found out that radial access, compared with femoral, was associated with a greater operator and patient radiation burden. ${ }^{26}$ Similarly, a systematic review and meta-analysis, which compared radiation parameters in relation to the access site, showed that radial access for interventional procedures was associated with a small yet significant increase in radiation exposure. ${ }^{27}$ No data were found in the literature regarding the association between survival in patients with ACS experiencing OHCA and radiation burden during invasive procedures. In a study of more than 3000 patients with non-ST-segment elevation myocardial infarction, Ding et $\mathrm{al}^{28}$ demonstrated that a larger dose of contrast agent significantly increased the risk of slow coronary blood flow and no-reflow phenomenon. Unfavorable effects of contrast agents administered during invasive procedures are known through their impact on renal function. ${ }^{29}$ No data could be found in the literature on the effects of the total amount of contrast agents administered during invasive procedures on survival in patients with ACS who had OHCA. Registries of ACSs may serve as a basis for analysis of various medical events, such as OHCA in the present study. It is of paramount importance in view of the implementation of the General Data Protection Regulation, which contributed to more restricted processing of personal health data in Poland.

Conclusions Based on our observation, factors influencing survival in patients with ACS and OHCA may be divided into 2 groups: well-documented risk factors and less commonly observed risk factors. The well-documented risk factors include age, a history of diabetes mellitus and renal failure, multivessel coronary artery disease on angiography, and time from pain onset to first medical contact. The total amount of contrast agent administered and patient radiation exposure during invasive procedures are considered less commonly observed risk predictors. Further research is needed to improve our understanding of the association between these less commonly investigated risk factors and survival in patients with ACS and OHCA. Furthermore, a national OHCA registry should be created to collect data useful for developing a model of healthcare, which will provide high-quality, safe services to patients with ACS and OHCA.

\section{SUPPLEMENTARY MATERIAL}

Supplementary material is available at www.mp.pl/kardiologiapolska.

\section{ARTICLE INFORMATION}

\section{CONFLICT OF INTEREST None declared.}

OPEN ACCESS This is an Open Access article distributed under the terms of the Creative Commons Attribution-NonCommercial-NoDerivatives $4.0 \mathrm{In}$ ternational License (CC BY-NC-ND 4.0), allowing third parties to download articles and share them with others, provided the original work is properly cited, not changed in any way, distributed under the same license, and used for noncommercial purposes only. For commercial use, please contact the journal office at kardiologiapolska@ptkardio.pl.

HOW TO CITE Sielski J, Kaziród-Wolski K, Siudak Z. Out-of-hospital cardiac arrest: data from the National Registry of Invasive Cardiology Procedures (ORPKI) in a long-term survival analysis of patients with acute coronary syndromes in a Polish region. Kardiol Pol. 2020; 78: 412-419. doi:10.33963/KP.15244

\section{REFERENCES}

1 Gräsner JT, Masterson S. EuReCa and international resuscitation registries. Curr Opin Crit Care. 2015; 21: 215-219.

2 Gräsner JT, Lefering R, Koster RW, et al. EuReCa ONE-27 Nations, ONE Europe, ONE registry: a prospective one month analysis of out-of-hospital cardiac arrest outcomes in 27 countries in Europe. Resuscitation. 2016; 105: 188-195.

3 Hawkes C, Booth S, Ji C, et al. Epidemiology and outcomes from out-of-hospital cardiac arrests in England. Resuscitation. 2017; 110: 133-140.

4 Nadolny K, Bujak K, Kucap M, et al. The Silesian Registry of Out-of-hospital Cardiac Arrest: study design and results of a three-month pilot study. Cardiol J. 2018 Nov 16. [Epub ahead of print].

5 Gach D, Nowak JU, Krzych LJ. Epidemiology of out-of-hospital cardiac arrest in Bielsko-Biała district: a 12- month analysis. Kardiol Pol. 2016; 74: 1180-1187.

6 Nadolny K, Gotlib J, Panczyk M, et al. The epidemiology of sudden cardiac arrest in prehospital care in the area of the Silesian voivodeship [in Polish]. Wiad Lek. 2018; 71: 193-200.

7 Roger VL, Go AS, Lloyd-Jones DM, et al. Executive summary: heart disease and stroke - 2012 update: a report from the American Heart Association. Circulation. 2012; 125: 188-197.

8 Atwood C, Eisenberg MS, Herlitz J, Rea TD. Incidence of EMS-treated out-of-hospital cardiac arrest in Europe. Resuscitation. 2005; 67: 75-80.

9 Hawkes C, Booth S, Ji C, et al. Epidemiology and outcomes from out-of-hospital cardiac arrests in England. Resuscitation. 2017; 110: 133-140.

10 Deasy C, Bray JE, Smith K, et al. Out-of-hospital cardiac arrests in the older age groups in Melbourne, Australia. Resuscitation. 2011; 82: 398-403.

11 Matsuyama T, Kitamura T, Kiyohara K, et al. Assessment of the 11-year nationwide trend of out-of-hospital cardiac arrest cases among elderly patients in Japan (2005-2015). Resuscitation. 2018; 131: 83-90.

12 Granfeldt A, Wissenberg M, Hansen SM, et al. Location of cardiac arrest and impact of pre-arrest chronic disease and medication use on survival. Resuscitation. 2017; 114: 113-120.

13 Sielski J, Kaziród-Wolski K, Solnica M, et al. Out-of-hospital cardiac arrest registry: preliminary results from the Świętokrzyskie Province. Kardiol Pol. 2019; 77: 710-712.

14 Januszek R, Siudak Z, Dziewierz A, et al. Predictors of in-hospital effectiveness and complications of rotational atherectomy (from the ORPKI Polish National Registry 2014-2016). Catheter Cardiovasc Interv. 2018; 92: 278-287.

15 Siudak Z, Tokarek T, Dziewierz A, et al. Reduced periprocedural mortality and bleeding rates of radial approach in ST-segment elevation myocardial infarction. Propensity score analysis of data from the ORPKI Polish National Registry. EuroIntervention. 2017; 13: 843-850.

16 Information on socio-economic situation of the country in 2017. Statistics Poland. https://stat.gov.pl/files/gfx/portalinformacyjny/pl/defaultaktualnosci/5468/6/22/1/ ludnosc_stan_i_struktura_w_przekroju_terytorialnym._stan_w_dniu_30.06.2017.pdf. Accessed October 2, 2019. 
17 Catheterization laboratories in Poland. The National Registry of Invasive Cardiology Procedures website. http://www.aisn.pl/pracownie/baza pracowni/59bf682f353fo. Accessed October 2, 2019.

18 Nadolny K, Ładny JR, Gałązkowski R, et al. Medical emergency team interventions in patients with ST-segment elevation myocardial infarction in Poland in 2018. Kardiol Pol. 2020; 78: 292-299.

19 Sadowski M, Janion-Sadowska A, Kurzawski J, et al. Is the time between onset of pain and restoration of patency of infarct-related artery shortened in patients with myocardial infarction? The effects of the Kielce Region System for Optimal Management of Acute Myocardial Infarction Kielce. Studia Medyczne. 2014; 30: $135-140$.

20 MedCalc Statistical Software. Version 19.1. MedCalc Software; 2019. https:// www.medcalc.org. Accessed September 15, 2019.

21 Patterson T, Perkins G, Hassan Y, et al. Temporal trends in identification, management, and clinical outcomes after out-of-hospital cardiac arrest: insights from the Myocardial Ischaemia National Audit Project database. Circ Cardiovasc Interv. 2018; 11: e005346.

22 Zeliaś A, Stępińska J, Anders J, et al. Ten-year experience of an invasive cardiology centrewith out-of-hospital cardiac arrest patients admitted for urgent coronary angiography Kardiol Pol. 2014; 72, 8: 687-699.

23 Podolec J, Wiewiórka $Ł$, Siudak Z, et al. Prevalence and clinical presentation of myocardial bridge on the basis of the National Polish Percutaneous Interventions Registry and the Classification of Rare Cardiovascular Diseases. Kardiol Pol. 2019; 77: 465-470.

24 Kroupa J, Knot J, Ulman J, et al. Characteristics and survival determinants in patients after out-of-hospital cardiac arrest in the era of 24/7 coronary intervention facilities. Heart Lung Circ. 2017; 26: 799-807.

25 Tateishi K, Abe D, Suzuki K, et al. Association between multivessel coronary artery disease and return of spontaneous circulation interval in acute coronary syndrome patients with out-of-hospital cardiac arrest. Int Heart J. 2019; 60: 1043-1049.

26 Sciahbasi A, Frigoli E, Sarandea A, et al. Radiation exposure and vascular access in acute coronary syndromes: the RAD-Matrix trial. J Am Coll Cardiol. 2017; 69: 2530-2537.

27 Plourde G, Pancholy SB, Nolan J, et al. Radiation exposure in relation to the arterial access site used for diagnostic coronary angiography and percutaneous coronary intervention: a systematic review and meta-analysis. Lancet. 2015; 386: 2192-2203.

28 Ding S, Shi Y, Sun $X$, et al. Contrast agent dose and slow/no-reflow in percutaneous coronary interventions: a case-control study of patients with non-ST-segment elevation acute coronary syndromes. Herz. 2019; 44: 69-75.

29 Bolognese L, Falsini G, Grotti S, et al. The contrast media and nephrotoxicity following coronary revascularization by primary angioplasty for acute myocardial infarction study: design and rationale of the CONTRAST-AMI study. J Cardiovasc Med (Hagerstown). 2010; 11: 199-206. 